\title{
Development and evaluation of controlled porosity osmotic pump for Nifedipine and Metoprolol combination
}

\author{
Rajagopal Kumaravelrajan ${ }^{1 *}$, Nallaperumal Narayanan ${ }^{2}$ and Venkatesan Suba ${ }^{3}$
}

\begin{abstract}
Background: A system that can deliver multi-drug at a prolonged rate is very important for the treatment of various chronic diseases such as diabetes, asthma and heart disease. Controlled porosity osmotic pump tablet (CPOP) system was designed to deliver Nifedipine (NP) and Metoprolol (MP) in a controlled manner up to $12 \mathrm{~h}$. It was prepared by incorporating drugs in the core and coated with various types (PVP, PEG-400 and HPMC) and levels (30, 40 and 50\% w/w of polymer) of pore former at a weight gain of $8,12 \& 15 \%$.

Results: Formulation variables like type and level of pore former and percent weight gain of membrane was found to affect the drug release from the developed formulations. Drug release was inversely proportional to the membrane weight but directly related to the level of pore former. Burst strength of the exhausted shell was inversely proportional to the level of pore former, but directly affected by the membrane weight. Results of scanning electron microscopy (SEM) studies showed the formation of pores in the membrane from where the drug release occurred. Dissolution models were applied to drug release data in order to establish the mechanism of drug release kinetics. In vitro release kinetics was subjected to superposition method to predict in vivo performance of the developed formulation.

Conclusion: The developed osmotic system is effective in the multi-drug therapy of hypertension by delivering both drugs in a controlled manner.

Keywords: Controlled porosity osmotic pump tablet CPOP, Controlled osmotic drug delivery, Nifedipine, Metoprolol, Osmotic pump
\end{abstract}

\section{Background}

Approximately one quarter of the total global population is affected by at least any one of the cardiovascular disease (CVD) [1]. It caused 2.3 million deaths in India in 1990 , which may double by year 2020, where hypertension alone contribute $57 \%$ of all stroke death and $24 \%$ of all coronary heart disease [2]. Hypertension is a common cause of cardiovascular disorders and is essentially associated with abnormal lipid and altered glucose metabolism $[3,4]$. Several studies revealed that a reduction in blood pressure reduces the risk and incidence of CVD [5,6]. Thus management of cardiovascular disease

\footnotetext{
* Correspondence: kumaravelrajan@yahoo.com

'Department of Pharmaceutics, C.L. Baid Metha College of Pharmacy,

Thoraipakkam, Chennai, Tamilnadu, India

Full list of author information is available at the end of the article
}

in particular the hypertension becomes important to improve health care system. Several multidrug therapies are prescribed for successful management of CVD, in which chronic diseases such as hypertension, diabetes, asthma etc., are treated using multidrug therapies, which are vulnerable to incidences of side-effects, poor patient compliance and slow improvement of patients. Nifedipine (NP) and Metoprolol tartarate (MP) are antihypertensive agents belonging to calcium channel blockers and $\beta$-blockers respectively. Generally, they are either used individually or as combination therapy to treat hypertension. Though NP and MP is administered as immediate release solid oral dosage form, a short elimination half life with significant fluctuation in plasma concentration necessitate it to be formulated into modified release dosage forms. Recently, it was
C Biomed Central 
reported that smooth plasma profile of NP by modified release dosage forms decreased morbidity and mortality, prevents myocardial infarction in diabetes mellitus patients and reduces atherosclerosis in carotid and coronary arteries [7]. These facts justify our interest in controlled release dosage form. We have recently developed controlled release formulation of NP and MP based on sandwiched osmotic delivery system [8]. Osmotic drug delivery was attempted since, though a number of design options are available to control the drug release from a dosage form, majority of the oral dosage form fall in the category of matrix, reservoir or osmotic systems. Drug release from osmotic system is independent of $\mathrm{pH}$ and gastrointestinal motility to a large extent [9]. The development of oral osmotic systems has a strong market potential, as evident from the marketed products and number of patents granted in the last few years [10].

From a technical standpoint, the controlled delivery of NP is difficult since it is practically insoluble in water and aqueous fluids due to its high crystalline nature and exhibits poor dissolution rate. Various attempts were made to improve the dissolution rate of NP which include solid dispersion in water soluble carriers such as urea [11], PVP (Polyvinyl pyrrolidone) [12], PVP-MCC and HIPC-MCC [13] complexation with cyclodextrin. Skalko et al., [14] reported the feasibility of using NPcyclodextrin complex as a core for microcapsule in order to obtain controlled release. Besides, recently Ramesh and Chowdary, [15] reported sustained release two layered tablet formulations of NP using NP-hydroxyproyl- $\beta$-cyclodextrin (1:1) inclusion complex. In the present investigation, 1:1 NP-hydroxyproyl- $\beta$-cyclodextrin (NH $\beta-\mathrm{CD})$ complex was used to improve NP dissolution rate and solubility.

There was a report of simultaneous delivery of drugs having extremely different solubility profile through elementary osmotic pump using highly water soluble drug as both osmotic agent and active ingredient to deliver it along with water insoluble drug [16]. Based on this report attempt was made to simultaneously deliver NP (water insoluble drug) and MP (highly water soluble drug) using the same approach. Instead, we tried controlled porosity osmotic pump (CPOP) system since preparation of CPOP is simple; it is not necessary to consider complicated side drilling and compared to other osmotic pump systems less excipients is required. The coating composition of CPOP includes pore-forming agent, which generates pores in contact with aqueous media [17]. It was observed that most of the core content releases through pores at a constant rate, where the release mechanism primarily is osmotic with simple diffusion playing a minor role. A zero-order delivery pattern was designed to produce plasma levels within the desired range. Different formulation variables were studied and optimized to achieve the desired release profile. Besides, the in vivo performance of the optimized formulation was predicted.

\section{Materials and methods \\ Materials}

Nifedipine (micronized) and Metoprolol tartarate were a kind gift sample from Madras Pharmaceuticals Private Limited, Chennai, India. Hydroxy propyl $\beta$-cyclodextrin $(\mathrm{H} \beta-\mathrm{CD})$ was purchased from Sigma-Aldrich, Bangalore. PVP (K-30) was purchased from s.d. Fine Chemicals Ltd, India. Hydroxy propyl methylcellulose (HPMC), Polyethylene glycol-400 (PEG-400) was obtained from Loba Chemie, Mumbai, India. Micro crystalline cellulose (MCC), magnesium stearate and aerosil were purchased from Rolex, Mumbai, India. Cellulose acetate (CA) was obtained from Eastman Chemical Company, Kingsport, U.S.A. All other solvents and chemicals used were of the analytical grade.

\section{Methods}

\section{Preparation of Nifedipine $\beta$-cyclodextrin inclusion complex}

Solid complex of NH $\beta$-CD were prepared in 1:1 ratio by co-precipitation method. NP was first dissolved in a small volume of acetone and then thoroughly mixed with $100 \mathrm{ml}$ of ethanolic solution of carrier in a round bottom flask. The solvent was evaporated under reduced pressure at $40^{\circ} \mathrm{C}$ (Rotary evaporator RE120, Buchi, Switzerland) and stored in dessicator.

\section{Preparation of tablets}

Core tablets were prepared by wet granulation and the composition is given in table 1 . For preparation of core tablets, the batch size was kept as 100 tablets. NH $\beta-C D$ and MP was mixed with starch and dicalcium phosphate and the blend was further mixed for $10 \mathrm{~min}$. The mixture was moistened with PVP solution in isopropyl alcohol and granulated by passing through 12 sieve. The granules were dried at $50^{\circ} \mathrm{C}$ (approximately $1 \mathrm{~h}$ ) after which they were passed through 18 sieve. These sized granules were then blended with magnesium stearate, talc and aerosil (all 120 sieve passed) and compressed

Table 1 Composition of core tablets of CPOP

\begin{tabular}{cc}
\hline Ingredients & Amount $(\mathbf{m g})$ \\
\hline NHß-CD Complex & 75 \\
Metoprolol tartarate & 55 \\
Starch & 10 \\
Dicalcium phosphate & 15 \\
PVP & 15 \\
Isopropyl alcohol & Q.S \\
Aerosil & 10 \\
Talc & 10 \\
Magnesium stearate & 02 \\
\hline
\end{tabular}


into tablets using a rotary tablet compression machine (Cadmac, India) fitted with $12 / 32$ inch deep concave punches. The core tablets were coated in an automated perforated pan (Cipweka, India). The composition of coating solution used for coating tablets is given in table 2. Various components of the coating solution were added to the solvent mixture in a sequential manner. The component added first was allowed to dissolve before the next component was added. Initially, pan was rotated at low speed (2-5 rev/min) and heated air was passed through the tablet bed. Coating process was started once the outlet air temperature reached $28^{\circ} \mathrm{C}$. Coating pan rpm was kept in the range of $12-15$ and coating solution was sprayed at the rate of $3-5 \mathrm{ml} / \mathrm{min}$. Coating was continued until desired weight gain was obtained on the active tablets. In all the cases, active tablets were dried at $50^{\circ} \mathrm{C}$ for $2 \mathrm{~h}$ before further evaluation.

\section{Evaluation of the developed formulations}

The developed formulations were subjected to release studies using USP-II dissolution apparatus (Electrolab, India) at $100 \mathrm{rpm}$. Dissolution medium used was phos-

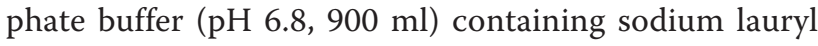
sulphate $0.5 \%$ maintained at $37 \pm 0.5^{\circ} \mathrm{C}$. The samples were withdrawn $(10 \mathrm{ml})$ at $0,2,4,6,8,10$ and $12 \mathrm{~h}$ intervals and replaced with an equivalent amount of fresh medium. The dissolution sample after filtration through $0.45 \mu \mathrm{m}$ cellulose acetate filter were analyzed using a validated UV spectrophotometric method at 340 $\mathrm{nm}$ for NP and $275 \mathrm{~nm}$ for MP. Each study was done in triplicate and the mean values were reported. After analyzing the drug content in the dissolution samples, the graph of cumulative percentage of drug release versus time was plotted. All experiments were carried out under strict protection from light to prevent undesirable photo-degradation of NP throughout the entire experimental procedure.

Mathematical comparisons of dissolution curves from various formulations provide an opportunity to test the similarity between two dissolution profiles. Fit factors $\left(f_{1}\right.$ and $f_{2}$ ) proposed by Moore and Flanner, [18] were used for comparing the dissolution profile of $\mathrm{pH}$ and

Table 2 Formulation variables of controlled porosity osmotic pump tablet

\begin{tabular}{lccccccccc}
\hline \multirow{2}{*}{$\begin{array}{c}\text { Coating } \\
\text { components }\end{array}$} & \multicolumn{7}{c}{ Formulation code } \\
\cline { 2 - 9 } & CF1 & CF2 & CF3 & CF4 & CF5 & CF6 & CF7 & CFW \\
\hline CA (\% w/v) & 4 & 4 & 4 & 4 & 4 & 4 & 4 & 4 \\
PVP (\% w/w of CA) & 30 & 40 & 50 & - & - & - & & 0 \\
PEG 400 (\% w/w of CA) & - & - & - & 40 & & 40 & 40 & - \\
HPMC (\% w/w of CA) & - & - & - & - & 40 & - & - & - \\
Thickness (\%) & 8 & 8 & 8 & 8 & 8 & 12 & 15 & 8 \\
\hline
\end{tabular}

agitation studies. An $f_{2}$ value of $\geq 50$ indicates similarity between two dissolution curves, whereas $f_{1}$ is used as an additional parameter to confirm the similarity when the value is $\leq 15$. For the calculation of $f_{1}$ and $f_{2}$ values, only one data point was taken into consideration after $85 \%$ of the drug was released.

\section{Formulation variables}

In order to optimize the formulation to release the drug at a constant zero-order release rate, level of pore former, type of pore former and coating thickness were used as formulation variables [19]. The respective formulation code and variables were given in table 2

\section{Effect of type and level of pore former}

To study the effect of pore former on the drug release, PVP, PEG-400 and HPMC were used as pore former at the level of $0,30,40$ and $50 \%(\mathrm{w} / \mathrm{w})$ of CA.

\section{Effect of coating thickness on drug release}

The tablets coated to three level of weight gain, such as 8,12 and $15 \%(w / w)$ in order to assess the effect of coating thickness on drug release.

\section{Burst strength}

Burst strength of the exhausted shells, after dissolution was determined to assure that the tablets would maintain their integrity in the gastrointestinal tract (GIT). Burst strength was determined as the force required to break/rupture the shells after dissolution studies. The texture analyzer (Instron 4501, India) with a $5 \mathrm{~kg}$ load cell and $25 \mathrm{~mm}$ aluminum cylindrical probe was utilized for this purpose. Test speed of $0.8 \mathrm{~mm} / \mathrm{s}$ with a distance of $2 \mathrm{~mm}$ was selected.

\section{Scanning electron microscopy studies}

In order to elucidate the mechanism of drug release from the developed formulations, surface of coated tablets before and after dissolution studies, was studied using scanning electron microscope (SEM). The samples were placed on a spherical brass stub (12 $\mathrm{mm}$ diameter) with a double backed adhesive tape. Small sample of the coating membrane was carefully cut from the exhausted shells (after dissolution studies) and dried at $50^{\circ} \mathrm{C}$ for 2 h. The mounted samples were sputter coated for $2 \mathrm{~min}$ with gold using fine coat ion sputter (JFC-1600, Jeol, Japan) with pressure of $8 \mathrm{~kg}$ Pascal and examined under SEM (JSM-6360, Jeol, Japan).

\section{Effect of $\mathrm{pH}$}

In order to study the effect of $\mathrm{pH}$ and to assure a reliable performance of the developed formulations independent of $\mathrm{pH}$, release studies of the optimized formulations were conducted in media of different $\mathrm{pH}$, simulated gastric fluid (SGF) pH 1.2, simulated intestinal fluid (SIF) pH 6.8 and pH change method (release media was SGF for first $2 \mathrm{~h}$, followed by SIF for the remaining period). The sample $(10 \mathrm{ml})$ was withdrawn at predetermined intervals and analyzed after filtration through $0.45-\mu \mathrm{m}$ cellulose acetate filter. The percentage 
cumulative drug release of optimized formulations at various $\mathrm{pH}$ was plotted and compared.

\section{Effect of agitational intensity}

In order to study the effect of agitational intensity of the release media, release studies of the optimized formulations were carried out in dissolution apparatus at various rotational speeds. Dissolution apparatus used was USP-II at 50, 100 and $150 \mathrm{rpm}$. Sample was withdrawn at pre-determined intervals and analyzed after filtration through $0.45 \mu \mathrm{m}$ cellulose acetate filter. The percentage cumulative drug release of optimized formulations at different agitational intensity was plotted and compared.

\section{Osmotic pressure measurement}

In order to confirm the mechanism of drug release, release studies of the optimized formulations were conducted in media of different osmotic pressure. To increase the osmotic pressure of the release media, sodium chloride (Osmotically effective solute) was added in SIF [20] and osmotic pressure was measured (Fiske micro osmometer, 210). The $\mathrm{pH}$ was adjusted to $6.8 \pm 0.05$. Release studies were carried out in $900 \mathrm{ml}$ of media using USP II dissolution test apparatus (100 rpm). Release profiles of the optimized formulations at different osmotic pressure was plotted and compared.

\section{Curve fitting analysis}

In order to describe the kinetics of drug release from controlled release preparations various mathematical equations have been proposed. Release data obtained was applied to different release models in order to establish the drug release mechanism and kinetics. Best goodness of fit test $\left(\mathrm{R}^{2}\right)$ was taken as criteria for selecting the most appropriate model [21].

\section{In vivo performance prediction of selected formulation}

Drug-release parameters $\left(R^{0}\right.$ and $\left.t_{\text {del }}\right)$ obtained from in vitro data and the pharmacokinetic properties of drugs were used for predicting blood drug concentrationtime profile from single dose and at steady state from multiple dosing. The method of superposition was used for the steady-state concentration predictions [22]. It was assumed that after the administration of a test dose of formulation, the drug would be released at a release rate $\left(R^{0}\right)$ for a period of time $\left(t_{\text {del }}\right)$ shorter than the selected dosing interval $(\tau)$. Values of $\mathrm{C}_{\text {ssmax }}$ and $\mathrm{C}_{\mathrm{ssmin}}$, maximum and minimum steady-state concentration, respectively, were compared with the desired values calculated from a theoretically developed controlled drug-release profile [23]. The predicted steady-state plasma level of developed formulation was compared with the desired levels by calculating the percent predicted error (\% PD) in $\mathrm{C}_{\mathrm{SSmax}}, \mathrm{C}_{\mathrm{ssmin}}$ and $\mathrm{AUC}_{0-\tau}$. Bioequivalence was anticipated [24] if the average \% PD was less than 15\%. The $\%$ PD was calculated using the following equation:

$$
\% \mathrm{PD}=\frac{\text { Predicted value }- \text { reference value }}{\text { Reference value }} \times 100
$$

\section{Result and Discussion}

\section{Desired drug release profile}

The purpose of this study was to develop a delivery system for short half life drugs NP and MP which can deliver these drugs in a controlled manner for $12 \mathrm{~h}$. The dose, the delivery time and the dosing interval are the key features for any temporal controlled release system. The desired steady-state concentration for NP to the therapeutically acceptable range is $15-75 \mathrm{ng} / \mathrm{ml}$ [25]. In the present study, steady state concentration was selected as $15-60 \mathrm{ng} / \mathrm{ml}$. Similarly, MP steady state plasma concentration was reported as $25-46 \mathrm{ng} / \mathrm{ml}$ [26]. The same plasma concentration was selected in this study. Taking different pharmacokinetic parameters of NP and MP into consideration, a zero-order based delivery strategy was designed to produce the desired plasma levels [22]. Series of simulations (using Microsoft Excel 2003) were performed and it was found that a delivery rate of $1.68 \mathrm{mg} / \mathrm{h}$ for a period of $5.19 \mathrm{~h}$ and $4.2 \mathrm{mg} / \mathrm{h}$ for a period of $8.8 \mathrm{~h}$ was found to meet the above requirements for NP and MP respectively.

\section{Formulation development}

The compatibility of NP, MP with the excipients used for formulation development was tested using differential scanning calorimetry (DSC). The changes in the endotherm observed in case of CPOP tablet (melting endotherm of $\mathrm{NH} \beta-\mathrm{CD}$ at $154.6^{\circ} \mathrm{C}$ and $\mathrm{MP}$ at $131.2^{\circ} \mathrm{C}$, Figure 1) for the original melting endotherm (figure not shown) of $\mathrm{NH} \beta-\mathrm{CD}\left(169.7^{\circ} \mathrm{C}\right)$ and $\mathrm{MP}\left(146.27^{\circ} \mathrm{C}\right)$ was minor. Hence it was clear that no specific interaction between the drug and excipients used in the present formulation. In general, both highly and poorly water-soluble drugs are not good candidates for osmotic delivery. As previous study demonstrated increased solubility of $\mathrm{NP}$ by complexation with $\mathrm{H} \beta-\mathrm{CD}$, we also prepared inclusion complex of $\mathrm{NH} \beta-\mathrm{CD}(1: 1)$ by co-precipitation method. Solubility of NP in distilled water at $25^{\circ} \mathrm{C}$ was $6.24 \mu \mathrm{g} / \mathrm{ml}$ whereas the solubility of prepared complex was found to be $15 \mu \mathrm{g} / \mathrm{ml}$. Phase solubility studies of $\mathrm{NH} \beta-\mathrm{CD}$ systems in water at $25^{\circ} \mathrm{C}$ revealed that the solubility of NP increased linearly with the increase in the concentration of $H \beta-C D$, showing a typical $A_{L}$-type phase solubility curve. This curve may be ascribed to the formation of a stoichiometric 1:1 complex of NP and $\mathrm{H} \beta$ $\mathrm{CD}$. The apparent 1:1 stability constant $\left(\mathrm{K}_{\mathrm{C}}\right)$ was calculated from the straight line of the phase solubility diagram and constant value was found to be $10.35 \mathrm{M}^{-1}$. 


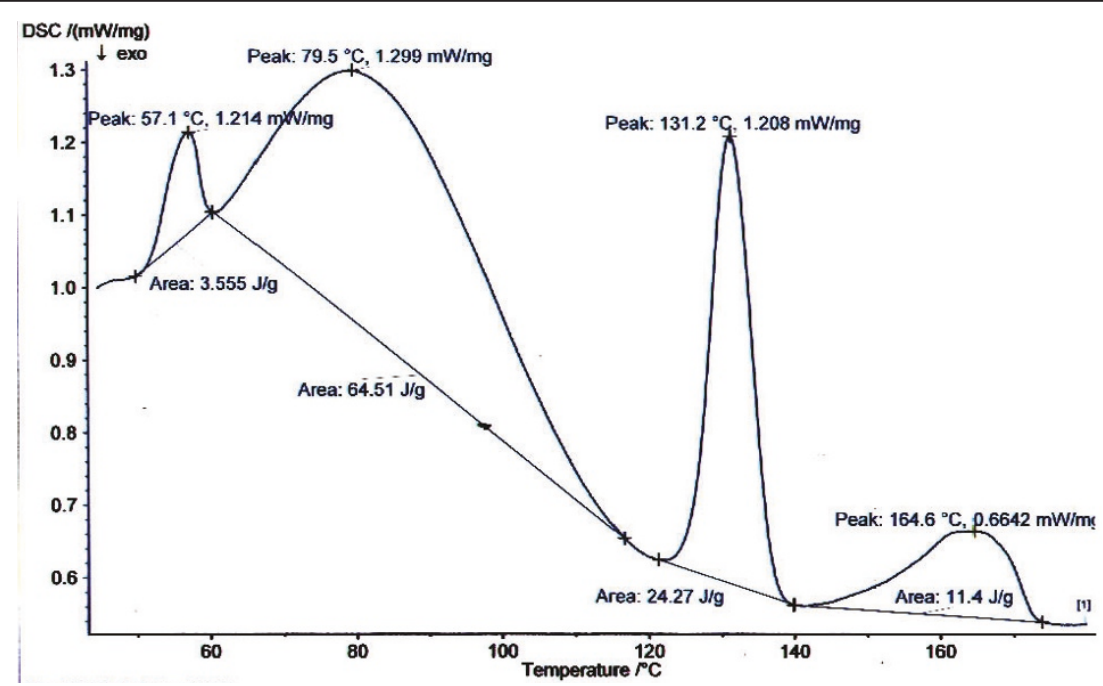

Figure 1 DSC thermogram of $\mathrm{NH} \beta-\mathrm{CD}$ and meoprolol combination CPOP

The dosage form developed consists of a tablet core of $\mathrm{NH} \beta-\mathrm{CD}$ and MP along with other excipients. Tablet core consists of drugs and other conventional excipients to form the core compartment. The core compartment is surrounded by a membrane consisting of a semipermeable membrane-forming polymer, water-soluble poreforming additives and at least one plasticizer capable of improving film forming properties of the polymers. The semipermeable membrane-forming polymer is permeable to aqueous fluids but substantially impermeable to the components of the core. In operation, the core compartment imbibes aqueous fluids from the surrounding environment across the membrane and dissolves the drug. The dissolved drugs are released through the pores created after leaching of water-soluble additive(s) in the membrane. CA was used as water insoluble polymer. PVP, PEG-400 and HPMC were tried as pore formers. Diethyl phthalate (DEP) 20\% was used as a plasticizer. We attempted to deliver NP and MP by adding highly water soluble MP in to the NH $\beta-C D$ tablets as both active agent and also as an osmotic agent. The release of NP was enhanced owing to osmotic effect of MP and further MP was also delivered simultaneously.

\section{Influence of tablet formulation variables on NP and MP release}

To study the influence of tablet formulation variables on drug release, tablets with various formulations were prepared, subsequently coated with the coating thickness of $8 \%$ and plasticized with $20 \%$ DEP.

\section{Effect of level of pore former}

To study the effect of level of pore former (PVP), core tablets were coated with coating composition containing
0, 30, 40 and 50\% (w/w) of PVP (formulations: CFW, CF1, CF2 and CF3 respectively). It was found that the drug release increased with increase in the level of pore former (Figure 2). As the level of pore former increases, the membrane becomes more porous after coming in contact with the aqueous environment, resulting in faster drug release. Other workers have also obtained similar results $[27,28]$. At levels up to $30 \%$ and $40 \%(w / w)$ of pore former, numbers of pores were sufficient to contribute to significant drug release. On the other hand, membrane that contained $50 \%(\mathrm{w} / \mathrm{w})$ of pore former; the release profile was faster since it became highly porous after coming in contact with water. Another parameter affected by the level of pore former was burst strength of the exhausted shells. The burst strength was inversely related to the initial level of pore former in the membrane. With the increase in level of PVP, the membrane became more porous after exposure to water, leading to decrease in its strength. Effect of level of PVP on burst strength is shown in table 3. Since, satisfactory drug release and adequate burst strength were obtained in case of formulations with $40 \%$ pore former level (CF2); this concentration was selected for further studies.

\section{Effect of type of pore former}

To study the effect of type of pore former, formulations CF2, CF4 and CF5 were prepared by coating core tablets of NP and MP with coating compositions containing different pore formers PVP 40\% (CF2), PEG-400 40\% (CF4) and HPMC 40\% (CF5). As evident from Figure 3, the type of pore former affected drug release and it is possible to achieve the desired release by using different types of pore formers. It has been reported that water- 


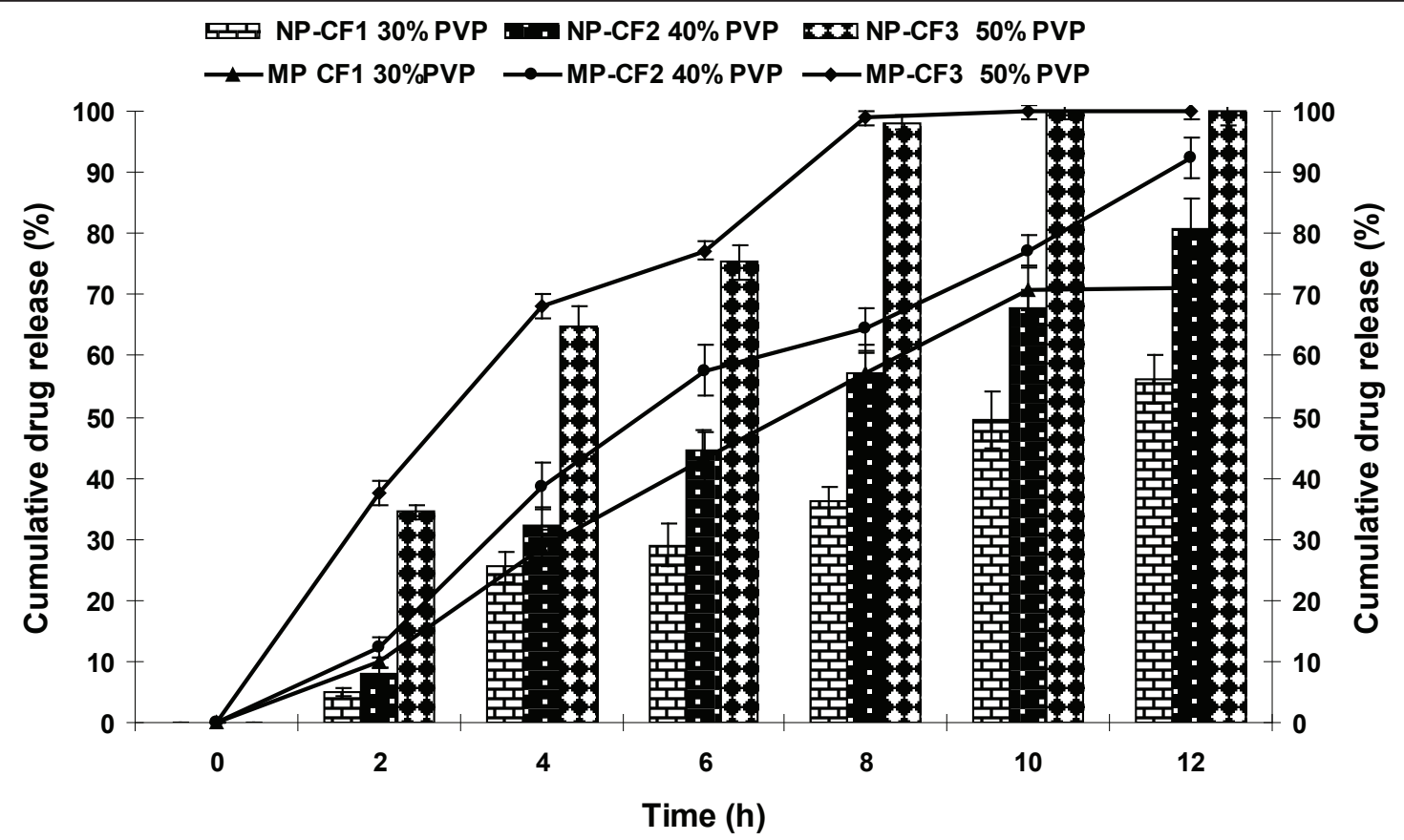

Figure 2 Effect of level of pore former on release of NP and MP.

soluble polymers such as PVP, PEG and HPMC may leach out of the coating, forming a porous film with increased permeability [29] or produce hydrated water filled HPMC regions within the membrane that allow drug transport across the film. The percentage drug release was more in case of PEG-400 as pore former, since it is more hydrophilic plasticizer than PVP and HPMC, it could be leached out easily and increases the flux rate of fluid. The poor drug release pattern of HPMC may result from the increased tortuosity or gel strength of the polymer. In addition to release, type of pore former also affected the burst strength of the exhausted shells (table 3 ) and this parameter should also be taken into consideration while selecting the pore former. The drug release pattern and the burst strength were satisfactory with the formulations containing PEG400 (CF4) as the pore former. This formulation was selected as the optimized formulation and used for further evaluation.

Table 3 Effect of level and type of pore former on burst strength

\begin{tabular}{lll}
\hline S.No & Pore former $(\% \mathbf{w} / \mathbf{w}$ of CA) & Burst strength (MPa) \\
\hline 1 & PVP (0) & 50 \\
2 & PVP (30) & 14.25 \\
3 & PVP (40) & 8.18 \\
4 & PVP (50) & 5.31 \\
5 & PEG-400 (40) & 18.25 \\
6 & HPMC (40) & 8.37 \\
\hline
\end{tabular}

\section{Effect of weight gain}

To study the effect of weight gain of the membrane, coating on the core tablets of NP was continued for sufficient duration so as to get tablets with different weight gain 8 (CF4), 12 (CF6) and 15\% (CF7). Release profile of $\mathrm{NP}$ and MP as a function of weight gain of the membrane is shown in Figure 4. Drug release was found to decrease with an increase in the weight gain of the membrane. The burst strength of these formulations were also observed (Figure 5). Though CF4 and CF6 showed higher drug release pattern, comparatively an approximate zero order release pattern and better burst strength was observed with CF6. In case of 15\% (CF7) thickness slow release pattern was observed. This is due to the increased polymer loading. The more the weight gain, the more would be the lag time. No bursting of the systems was observed during the dissolution run in any of the formulations. In addition, exhausted tablets (after $12 \mathrm{~h}$ of dissolution studies) were evaluated for burst strength to assure that the tablets maintain their integrity in GIT and do not lead to dose dumping.

The strength of mechanical destructive forces in the GIT of humans and dogs has been reported to be 1.9 $\mathrm{N}$ (approximately $190 \mathrm{~g}$ ) and $3.2 \mathrm{~N}$ (approximately $320 \mathrm{~g})$, respectively [30,31]. In a previous study, it has been reported that osmotic pumps having the burst strength in the range of 500-600 g were intact in the GIT of dogs while those having burst strength of around $200 \mathrm{~g}$ were compromised [32]. In all cases of our investigation the value of burst strength is much 


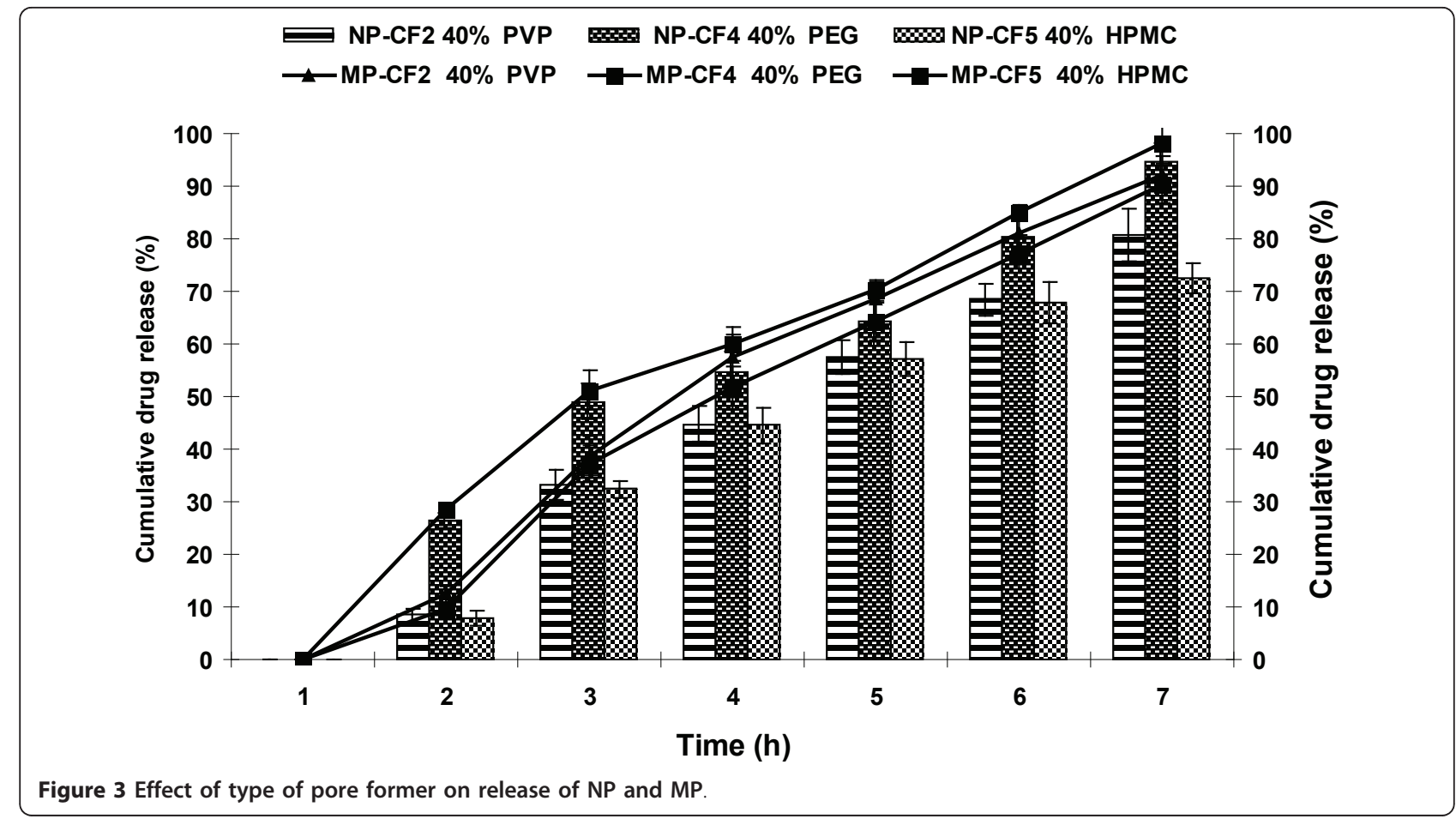

higher than the mechanical destructive forces in GIT, thus assuring that the formulations can be expected to remain intact in GIT without any incidence of dose dumping. It was found that an approximate zeroorder release rate pattern up to $12 \mathrm{~h}$ and sufficient burst strength was obtained in the case of the $12 \%$ coating thickness. Hence CF6, PVP-40\% and weight gain of $12 \%$ was used as optimized formulation for further evaluations.
Kinetics and Mechanism of drug release

Drug-release data from the optimized formulation was fitted to various kinetic models to elucidate the mechanism and kinetics of drug release (table 4). Best goodness of fit test $\left(R^{2}\right)$ was taken as criteria for selecting the most appropriate model. The data fit well into the zero order kinetics. The compatible fit of the zero order kinetics indicated that the drug release is controlled by a concentration independent release mechanism.

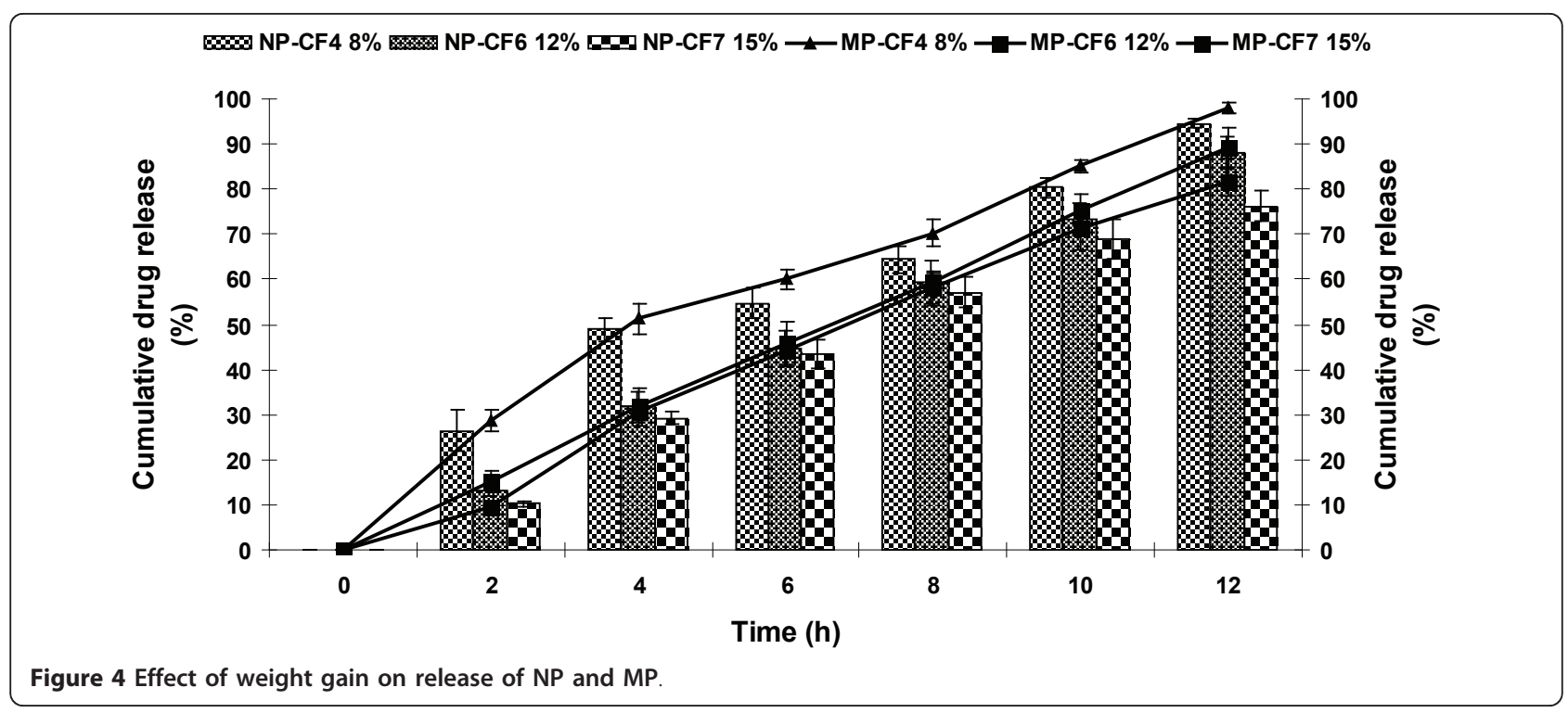




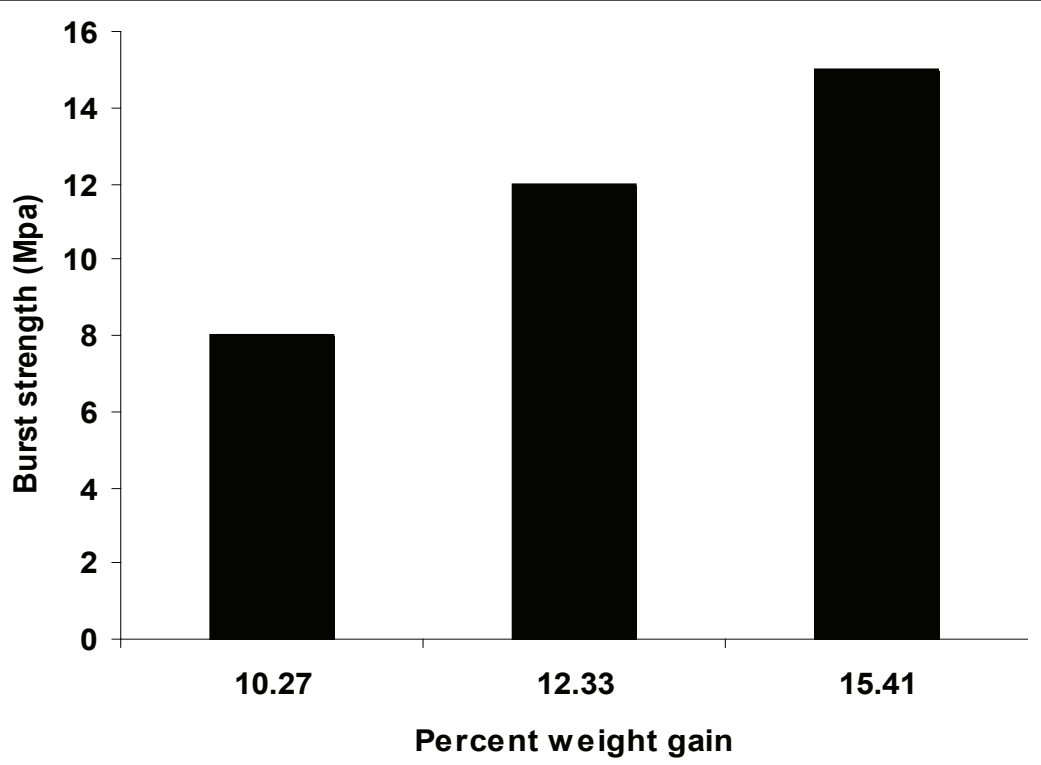

Figure 5 Burst strength of the membrane as function of weight gain.

To investigate the changes in the membrane structure, surface of coated tablets was studied using SEM. Figure 6, $7 \& 8$ showed SEM micrographs of membrane surface of developed formulations CF2, CF4 and CF5 containing $40 \%$ of PVP, PEG-400 and HPMC before and after dissolution studies. After dissolution studies, coating was intact without any cracks. However, there was formation of channels/pores in the membrane, which possibly acted as exit ports for the drug.

Figure $6 \mathrm{a}, 7 \mathrm{a}$ and $8 \mathrm{a}$ showed the membrane structure before dissolution studies. In all the cases, no significant difference was observed between different types of pore former (PVP, PEG-400 and HPMC). The surface of coated tablet was smooth before coming into contact with the aqueous environment and the coats appeared to be free of point defects.

Table 4 Fitting of NP and MP release data of the optimized formulation (CF6) according to various mathematical models

\begin{tabular}{|c|c|c|c|c|c|c|c|c|}
\hline \multirow[t]{3}{*}{ Model } & \multicolumn{8}{|c|}{ Parameters used to assess the fit of model } \\
\hline & \multicolumn{2}{|c|}{$\mathrm{R}^{2}$} & \multicolumn{2}{|c|}{ Intercept } & \multicolumn{2}{|c|}{$\mathrm{K}$} & \multicolumn{2}{|c|}{ AIC } \\
\hline & NP & MP & NP & MP & NP & MP & NP & MP \\
\hline $\begin{array}{l}\text { Zero } \\
\text { order }\end{array}$ & 0.9986 & 0.9994 & 0.239 & 0.741 & 1.48 & 3.94 & 5.08 & -0.99 \\
\hline $\begin{array}{l}\text { First } \\
\text { order }\end{array}$ & -0.9174 & -0.9134 & 2.09 & 2.09 & -0.16 & -0.17 & -30.32 & -29.39 \\
\hline Higuchi & 0.9649 & 0.9671 & -11.68 & -11.35 & 25.6 & 25.84 & 33.92 & 33.72 \\
\hline \multicolumn{9}{|c|}{$\mathrm{R}^{2}$-Goodness of fit. } \\
\hline $\begin{array}{l}\mathrm{K} \text { - Release } \\
\text { in } \% \mathrm{~h}^{1 / 2} \mathrm{fo} \\
\mathrm{AIC} \text { - Akaik }\end{array}$ & 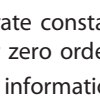 & rrite & 0. & +1 & us & st & 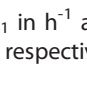 & $\begin{array}{l}\text { ad } K_{H} \\
\text { ely). }\end{array}$ \\
\hline
\end{tabular}

When comparison was made among the membrane containing different types of pore formers after dissolution studies, it was found that the membrane that contained PVP (Figure 6b), PEG-400 (Figure 7b) and HPMC (Figure $8 \mathrm{~b}$ ) developed pores. But the size and number of pores are more in case of PEG-400. The membrane becomes more porous, because of leaching of pore former from the membrane.

\section{Effect of $\mathrm{pH}$}

In order to study the effect of $\mathrm{pH}$ on drug release, release studies were conducted in media of different $\mathrm{pH}$. To study the effect of $\mathrm{pH}$ and to assure a reliable $i n-$ vivo performance, release study of the optimized formulation was conducted according to $\mathrm{pH}$ change method and compared with release profile in SIF ( $\mathrm{pH} 6.8$ ). Table 5 showed release of NP and MP from optimized formulation of CPOP (CF6) in $\mathrm{pH} 1.2 ; \mathrm{pH}$ change method and $\mathrm{pH} 6.8$ respectively. The $f_{1}$ and $f_{2}$ values were found to be 3 and 78 (between $\mathrm{pH} 1.2$ and $\mathrm{pH}$ 6.8), 3 and 76 (between $\mathrm{pH}$ change method and $\mathrm{pH}$ 6.8) for NP and 2 and 81 (between $\mathrm{pH} 1.2$ and $\mathrm{pH}$ 6.8), 3 and 77 (between $\mathrm{pH}$ change method and $\mathrm{pH}$ 6.8) for MP respectively. As can be seen from table 5 , release profile is similar in all the media demonstrating that the developed formulations show $\mathrm{pH}$-independent release.

\section{Effect of agitational intensity}

Drug release from osmotic pumps to a large extent is independent of agitation intensity of the release media. To study the effect of agitational intensity of the release media, release studies of the optimized formulation of 


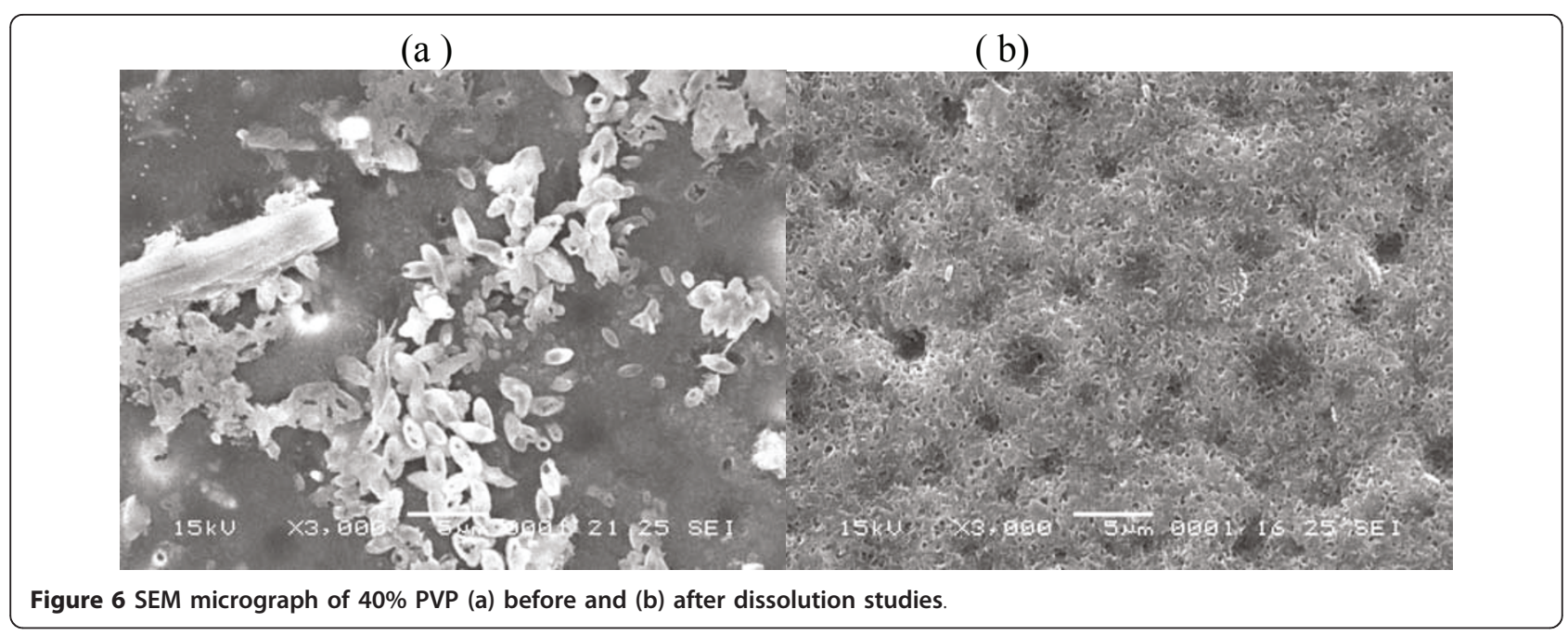

CPOP (CF6) were carried out in USP dissolution apparatus type II at varying rotational speed (50, 100 and $150 \mathrm{rpm})$. It is clearly evident from table 6 that the release of NP and MP from CPOP is independent of the agitational intensity. The $f_{1}$ and $f_{2}$ values were found to be 5 and 69 (between pH 1.2 and $\mathrm{pH} 6.8$ ), 4 and 69 (between $\mathrm{pH}$ change method and $\mathrm{pH}$ 6.8) for NP and 4 and 67 (between pH 1.2 and $\mathrm{pH}$ 6.8), 3 and 77 (between $\mathrm{pH}$ change method and $\mathrm{pH}$ 6.8) for MP respectively. Hence, it can be expected that the release from the developed formulation will be independent of the hydrodynamic conditions of the absorption site.

\section{Effect of osmotic pressure}

The effect of osmotic pressure on the optimized formulation was studied in media of different osmotic pressure, and the release profile with varying osmotic pressure is depicted in table 7 . The results of release studies of optimized formulations in media of different osmotic pressure indicated that, the drug release is highly dependent on the osmotic pressure of the release media. NP and MP release from the formulations decreased as the osmotic pressure of the media increased. The release was inversely related to the osmotic pressure of the release media. This finding confirms that the mechanism of drug release is by the osmotic pressure.

\section{Prediction of in vivo concentration-time profile from in vitro data}

Method of superposition was used to predict steady state plasma levels of NP and MP after administration of CF6 formulation [22]. A steady state drug concentration-time profile for the optimized tablet was predicted using its in vitro zero order kinetic release rate. Because the release rate of drugs from the tablets was slightly lower than the desired level, the predicted drug concentrations were also proportionately lower to the desired

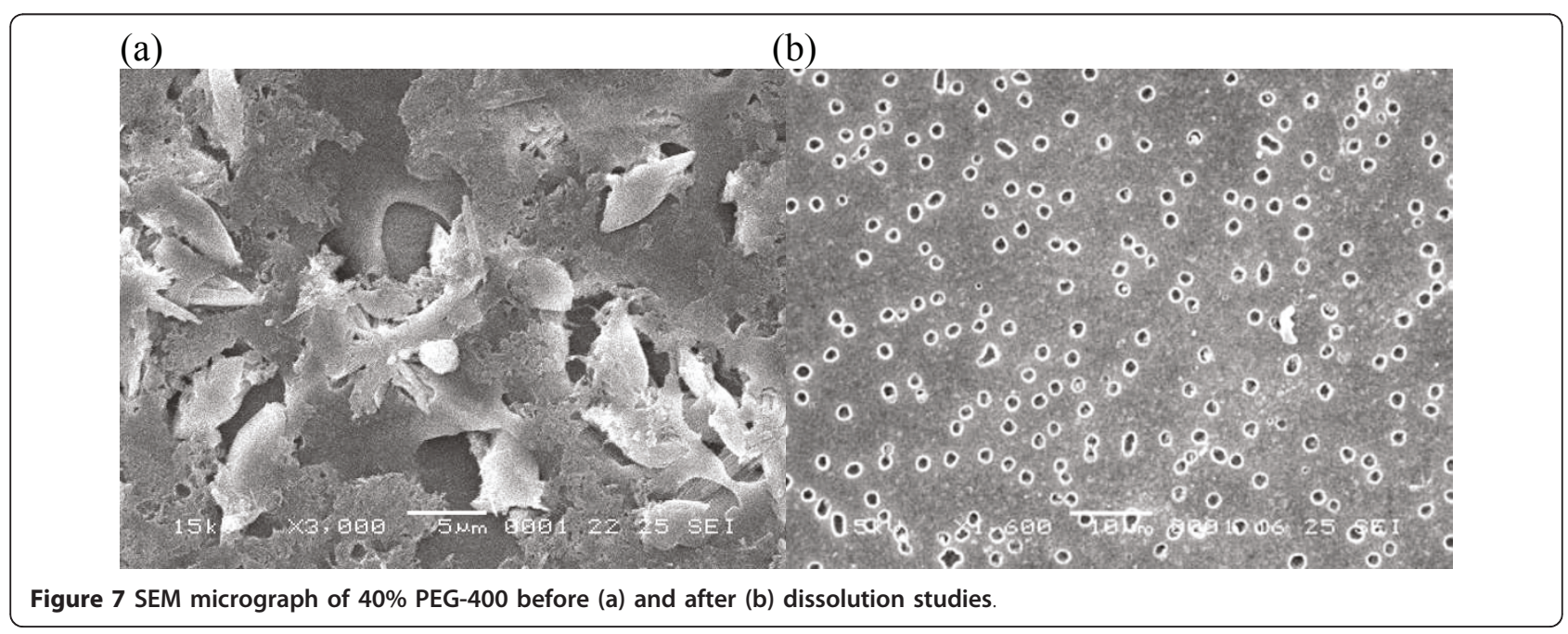




\section{(a)}

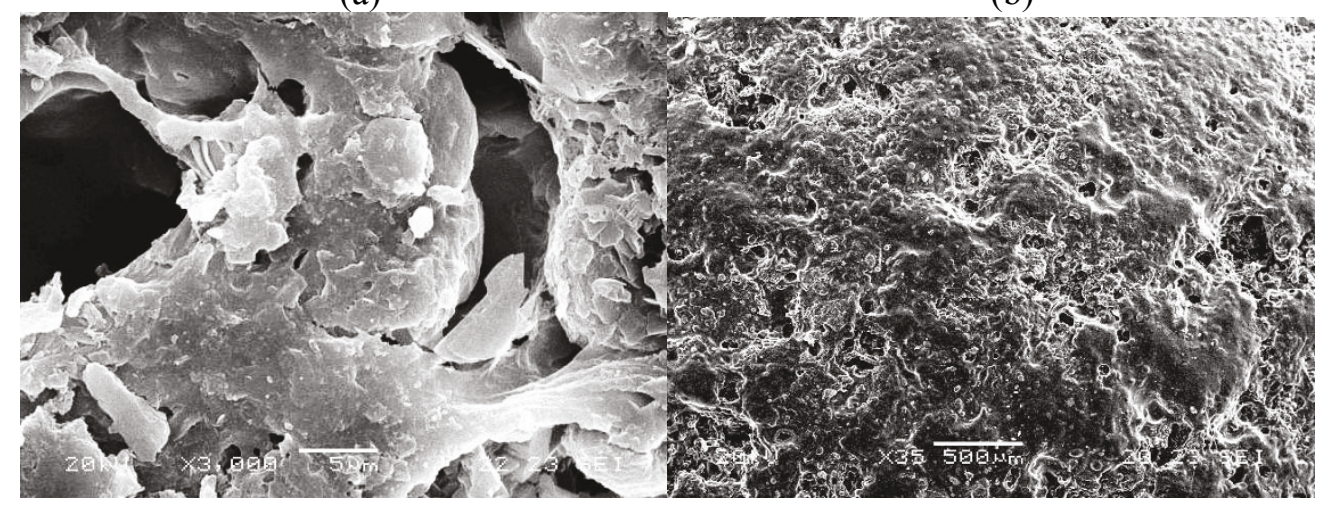

Figure 8 SEM micrograph of 40\% HPMC before (a) and after (b) dissolution studies

Table 5 Effect of $\mathrm{pH}$ on release of NP and MP from CF6 $(n=3)$

\begin{tabular}{|c|c|c|c|c|c|c|}
\hline \multirow{3}{*}{$\begin{array}{c}\text { Time } \\
\text { (h) }\end{array}$} & \multicolumn{6}{|c|}{ Cumulative $\%$ release \pm SEM } \\
\hline & \multicolumn{3}{|c|}{ NP } & \multicolumn{3}{|c|}{ MP } \\
\hline & $\mathrm{pH} 6.8$ & $\mathrm{pH} 1.2$ & pH change & $\mathrm{pH} 6.8$ & $\mathrm{pH} 1.2$ & pH change \\
\hline 0 & $0.00 \pm 0.00$ & $0.00 \pm 0.00$ & $0.00 \pm 0.00$ & $0.00 \pm 0.00$ & $0.00 \pm 0.00$ & $0.00 \pm 0.00$ \\
\hline 2 & $13.28 \pm 0.68$ & $12.60 \pm 1.30$ & $13.40 \pm 0.71$ & $15.31 \pm 1.71$ & $12.52 \pm 2.31$ & $12.02 \pm 1.35$ \\
\hline 4 & $31.81 \pm 1.23$ & $29.50 \pm 1.89$ & $27.40 \pm 1.12$ & $31.71 \pm 1.20$ & $28.50 \pm 2.44$ & $26.50 \pm 2.50$ \\
\hline 6 & $44.74 \pm 1.50$ & $41.31 \pm 2.80$ & $39.08 \pm 1.54$ & $45.66 \pm 3.12$ & $42.12 \pm 2.09$ & $40.82 \pm 1.51$ \\
\hline 8 & $59.28 \pm 1.91$ & $55.90 \pm 2.30$ & $53.62 \pm 2.31$ & $59.41 \pm 2.96$ & $56.95 \pm 2.61$ & $53.40 \pm 2.97$ \\
\hline 10 & $73.15 \pm 0.21$ & $70.12 \pm 2.67$ & $67.93 \pm 3.02$ & $75.27 \pm 2.31$ & $72.85 \pm 3.42$ & $70.16 \pm 2.46$ \\
\hline 12 & $88.14 \pm 1.10$ & $85.41 \pm 1.80$ & $85.20 \pm 2.86$ & $89.13 \pm 1.90$ & $87.09 \pm 3.79$ & $86.40 \pm 1.83$ \\
\hline
\end{tabular}

Table 6 Effect of agitational intensity on release of NP and MP from CF6 ( $n=3$ )

\begin{tabular}{|c|c|c|c|c|c|c|}
\hline \multirow[b]{3}{*}{$\begin{array}{c}\text { Time } \\
\text { (h) }\end{array}$} & \multicolumn{6}{|c|}{ Cumulative $\%$ of release \pm SEM } \\
\hline & \multicolumn{3}{|c|}{ NP } & \multicolumn{3}{|c|}{ MP } \\
\hline & 100 RPM & 50 RPM & 150 RPM & 100 RPM & 50 RPM & 150 RPM \\
\hline 0 & $0.00 \pm 0.00$ & $0.00 \pm 0.00$ & $0.00 \pm 0.00$ & $0.00 \pm 0.00$ & $0.00 \pm 0.00$ & $0.00 \pm 0.00$ \\
\hline 2 & $8.50 \pm 0.71$ & $13.28 \pm 0.68$ & $14.50 \pm 1.30$ & $11.41 \pm 2.31$ & $15.31 \pm 1.71$ & $18.21 \pm 1.35$ \\
\hline 4 & $27.35 \pm 1.12$ & $31.81 \pm 1.23$ & $34.21 \pm 1.89$ & $27.80 \pm 2.44$ & $31.71 \pm 1.20$ & $33.4 \pm 2.5$ \\
\hline 6 & $38.46 \pm 1.54$ & $44.74 \pm 1.50$ & $47.41 \pm 2.80$ & $41.04 \pm 2.09$ & $45.66 \pm 3.12$ & $49.50 \pm 1.51$ \\
\hline 8 & $55.92 \pm 2.31$ & $59.28 \pm 1.91$ & $62.53 \pm 2.30$ & $55.71 \pm 2.61$ & $59.41 \pm 2.96$ & $63.21 \pm 2.97$ \\
\hline 10 & $65.13 \pm 3.02$ & $73.15 \pm 0.21$ & $77.08 \pm 2.67$ & $71.58 \pm 3.42$ & $75.27 \pm 2.31$ & $77.81 \pm 2.46$ \\
\hline 12 & $83.53 \pm 2.86$ & $88.14 \pm 1.10$ & $91.73 \pm 1.80$ & $85.02 \pm 3.79$ & $89.13 \pm 1.90$ & $93.41 \pm 1.83$ \\
\hline
\end{tabular}

Table 7 Effect of osmotic pressure on release of NP and MP from CF6

\begin{tabular}{|c|c|c|c|c|c|c|c|c|}
\hline \multirow{3}{*}{$\begin{array}{c}\text { Time } \\
\text { (h) }\end{array}$} & \multicolumn{8}{|c|}{ Cumulative $\%$ of drug release } \\
\hline & \multicolumn{4}{|c|}{ NP } & \multicolumn{4}{|c|}{ MP } \\
\hline & CF6 & $7.8 \mathrm{~atm}$ & $13.85 \mathrm{~atm}$ & $21.27 \mathrm{~atm}$ & CF6 & $7.8 \mathrm{~atm}$ & $13.85 \mathrm{~atm}$ & $21.27 \mathrm{~atm}$ \\
\hline 0 & 0.00 & 0.00 & 0.00 & 0.00 & 0.00 & 0.00 & 0.00 & 0.00 \\
\hline 2 & 13.28 & 8.50 & 5.20 & 3.10 & 15.31 & 10.20 & 6.21 & 3.45 \\
\hline 4 & 31.81 & 24.30 & 18.40 & 12.30 & 31.71 & 24.60 & 18.20 & 12.00 \\
\hline 6 & 44.74 & 33.20 & 30.10 & 22.40 & 45.66 & 38.60 & 29.50 & 21.40 \\
\hline 8 & 59.28 & 48.40 & 41.50 & 29.50 & 59.41 & 50.00 & 39.50 & 30.20 \\
\hline 10 & 73.15 & 65.00 & 56.40 & 45.30 & 75.27 & 66.14 & 58.70 & 50.36 \\
\hline 12 & 88.14 & 79.10 & 68.00 & 58.60 & 89.13 & 79.50 & 70.13 & 64.20 \\
\hline
\end{tabular}




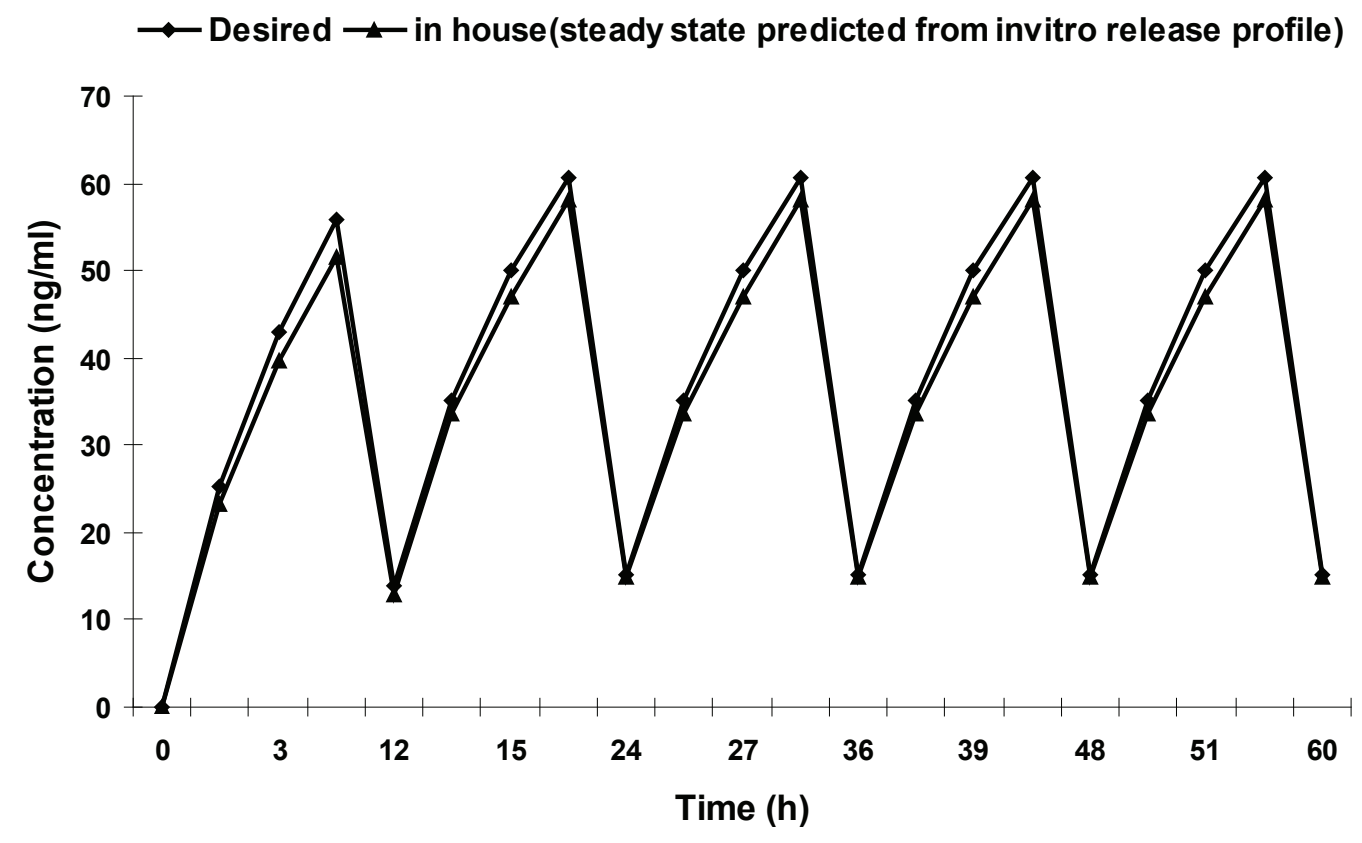

Figure 9 Predicted steady-state concentration of NP in comparison with the desired profile.

concentrations. Prediction of steady-state levels of NP and MP after administration of a test dose of formulation showed that peak plasma levels were 58 (NP) and $45.98 \mathrm{ng} / \mathrm{ml}$ (MP) but falls to14.8 (NP) and $25 \mathrm{ng} / \mathrm{ml}$ (MP) at steady state (Figure 9, 10). The predicted
$\mathrm{C}_{\mathrm{SSmax}}, \mathrm{C}_{\mathrm{SSmin}}$ and $\mathrm{AUC}_{0-\tau}$ after administration of formulation of NP and MP, in comparison with the desired ones are listed in table 8 . The $\% \mathrm{PD}$ of the steady-state parameters of CF6 formulation was calculated taking the data of desired profile as the reference. The absolute \%

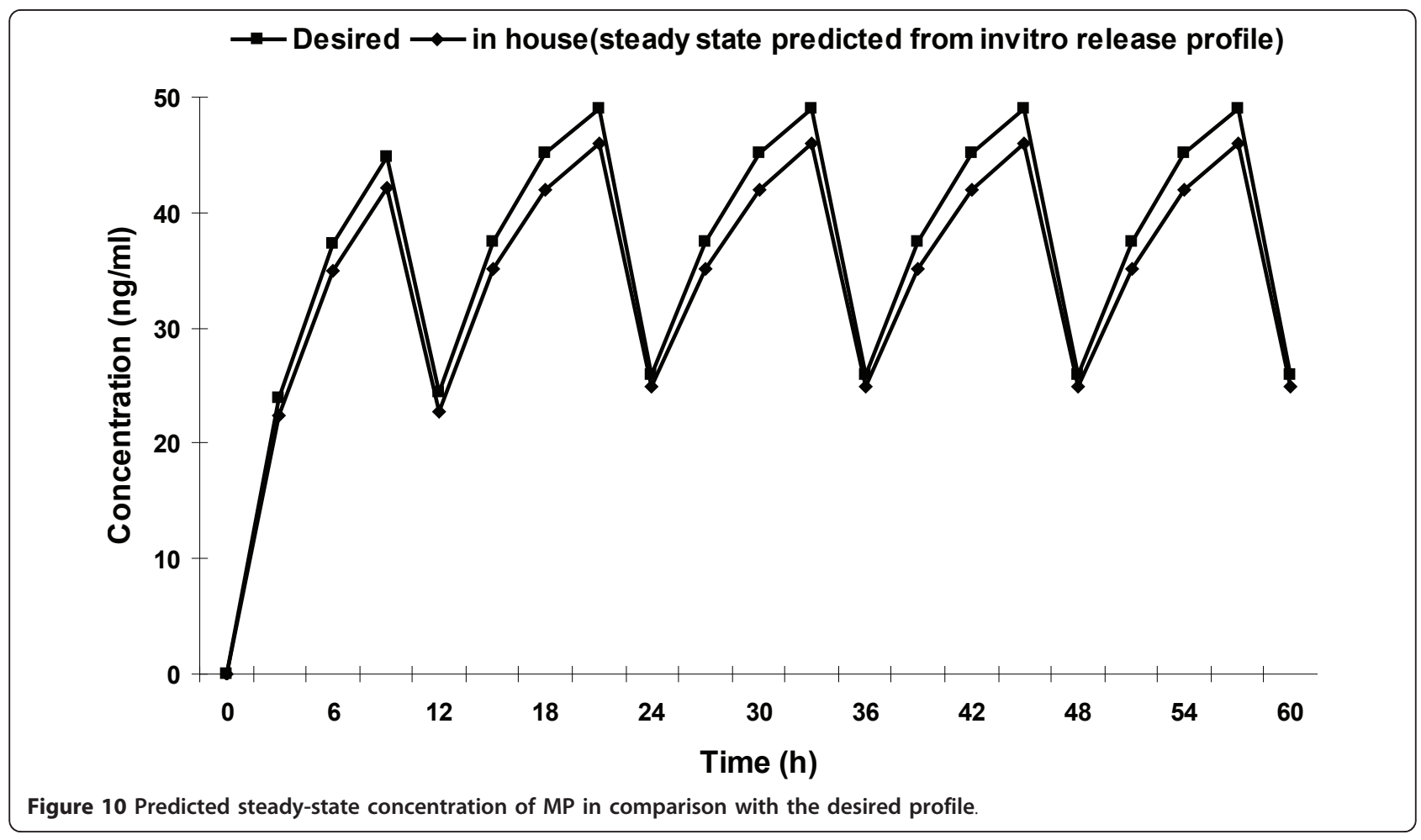


Table 8 Predicted in vivo performance of the developed formulation for NP and MP

\begin{tabular}{|c|c|c|c|c|c|c|}
\hline \multirow[t]{2}{*}{ Predicted parameters } & \multicolumn{2}{|c|}{ NP } & \multirow{2}{*}{$\begin{array}{l}\text { PD } \\
\text { (\%) }\end{array}$} & \multicolumn{2}{|c|}{ MP } & \multirow[t]{2}{*}{ PD (\%) } \\
\hline & Desired $^{a}$ & Formulation $^{\mathbf{b}_{*}}$ & & Desired $^{c}$ & Formulation $^{\mathrm{d}_{*}}$ & \\
\hline Cmax (ng/ml) after a single dose study & 55.85 & 51.83 & -7.2 & 44.85 & 42.08 & -6.1 \\
\hline $\mathrm{Cmax}(\mathrm{ng} / \mathrm{ml})$ at steady state & 60.68 & 58.0 & -4.4 & 49 & 45.98 & -6.1 \\
\hline $\operatorname{Tmax}(\mathrm{h})$ & 5.19 & 5.18 & -.19 & 8.921 & 8.906 & -0.16 \\
\hline $\mathrm{Cmin}(\mathrm{ng} / \mathrm{ml})$ at steady state & 15.16 & 14.8 & -2.3 & 26 & 25 & -3.8 \\
\hline$A U C_{0-t}(\mathrm{ng} \mathrm{h} / \mathrm{ml})$ after a single dose study & 405 & 374 & -7.6 & 357 & 334 & -6.4 \\
\hline$A U C_{0-t}(\mathrm{ng} \mathrm{h} / \mathrm{ml})$ at steady state & 669 & 639 & -4.6 & 661 & 619 & -6.3 \\
\hline
\end{tabular}

${ }^{a}$ Predicted from desired zero-order delivery profile (NP) (dose $=20 \mathrm{mg}, R^{0}=1.677 \mathrm{mg} / \mathrm{h}$, and $t_{\text {del }}=5.19 \mathrm{~h}$ ).

b*Predicted from drug release studies (NP-Formulation CF6) (dose $=20.13 \mathrm{mg}, R^{0}=1.479 \mathrm{mg} / \mathrm{h}$, and $t_{\text {Del }}=5.18 \mathrm{~h}$ ).

${ }^{c}$ Predicted from desired zero-order delivery profile (MP) (dose $=50 \mathrm{mg}, R^{0}=4.20 \mathrm{mg} / \mathrm{h}$, and $t_{\text {Del }}=8.79 \mathrm{~h}$ ).

$\mathrm{d}_{*}$ Predicted from drug release studies (MP-Formulation CF6) (dose $=50.49 \mathrm{mg}, R^{0}=3.94 \mathrm{mg} / \mathrm{h}$, and $t_{\text {Del }}=8.90 \mathrm{~h}$ ).

PD was found to be less than $15 \%$, ensuring that the formulation will produce plasma levels close to the desired ones. Thus, it can be concluded that the developed formulation (CF6) will produce plasma levels well within the therapeutic range and similar to those produced by the desired zero order delivery profile.

\section{Conclusion}

In the present study an oral osmotic system was developed that can deliver NP and MP simultaneously. This study suggests that drug release from these systems is controlled by osmotic pressure as the major mechanism; release pattern followed zero order kinetics and independent of environmental medium and the mobility of the gastrointestinal tract. The feasibility of extending the zero order release pattern of both the drugs were better achieved with controlled porosity osmotic pump tablet system between 10-12 h. The prototype design of the system could be applied to other combinations of drugs (one slightly water soluble or insoluble drug and another freely water soluble drug) used in cardiovascular diseases, diabetes etc.

\section{Conflict of interests}

The authors declare that they have no competing interests.

\footnotetext{
Author details

'Department of Pharmaceutics, C.L. Baid Metha College of Pharmacy, Thoraipakkam, Chennai, Tamilnadu, India. ${ }^{2}$ Department of Pharmaceutics, College of Pharmacy, Madras Medical College, Chennai, Tamilnadu, India. ${ }^{3}$ Department of Pharmacology, National Institute of Siddha, Chennai, Tamilnadu, India.
}

\section{Authors' contributions}

RK carried out the formulation, in vitro characterization and drafted the manuscript. NR participated in its design and coordination and helped to draft the manuscript. VS helped out in the prediction of in vivo performance from the in vitro release characteristic studies. All authors read and approved the final manuscript.
Received: 12 February 2011 Accepted: 11 April 2011

Published: 11 April 2011

\section{References}

1. Heart disease and stroke statistics-2004 update. American Heart Association, Dallas, USA; 2004.

2. Gupta R: Trends in hypertension epidemiology in India. J Hum Hypertens 2004, 18: 73-78.

3. Kannel WB: Pressure as a cardiovascular risk factor: Prevention and Treatment. JAMA 1996, 275(20): 1571-1576.

4. Weber MA: Hypertension as a risk factor syndrome: therapeutic implications. AMJ Med 1993, 94(4A): 24-315.

5. ALLHAT Officers and Coordinators for the ALLHAT Collaborative Research Group: Major outcomes in high-risk hypertensive patients randomized to angiotensin-converting enzyme inhibitor or calcium channel blocker vs. diuretic: the Hypertensive and Lipid-Lowering Treatment to Prevent Heart Attack (ALLHAT). JAMA 2002, 288: 2981-2997.

6. Hata, Yoshiya : A placebo-controlled study of the effect of sour milk on blood pressure in hypertensive subjects. American Journal of Clinical Nutrition 1996, 64: 767-71.

7. Sorkin EM, Clissold SP, Brogden R: Nifedipine. A review of its pharmacodynamic and pharmacokinetic properties, and therapeutic efficacy, in ischaemic heart disease, hypertension and related cardiovascular disorders. Drugs 1985, 30(3): 182-274.

8. Kumaravelrajan R, Narayanan N, Suba V, Bhaskar K: Simultaneous delivery of Nifedipine and Metoprolol tartarate using sandwiched osmotic pump tablet system. Int J Pharm 2010, 399(1-2): 60-70.

9. Theeuwes F, Swanson DR, Guittard G, Ayer A, Khanna S: Osmotic delivery systems for the $\beta$-adrenoceptor antagonists Metoprolol and Oxprenolol: Design and evaluation of systems for once-daily administration. $\mathrm{Br} J \mathrm{Clin}$ Pharmacol 1985, 19(Suppl 2): 69-76.

10. Santus G, Baker RW: Osmotic drug delivery: a review of the patent literature. J Control Release 1995, 35: 1-21.

11. Sumnu M: Increasing dissolution rate and gastrointestinal absorption of Nifedipine via solid dispersion. STP Pharma 1986, 2(14): 214-220.

12. Sugimoto L, Kuchiki H, Nakagawa K, Tohgo I, Iwane, Takahashi K: Dissolution and absorption of Nifedipine from Nifedipine-polyvinyl pyrrolidone coprecipitate. Drug Dev Ind Pharm 1980, 6(2): 37-160.

13. Chowdary KPR, Reddy GK: Complexes of Nifedipine with beta and hydroxypropyl beta cyclodextrins in the design of Nifedipine SR tablets. Ind J Pharm Sci 2002, 24(2): 142-146.

14. Skalko N, Brandl M, Ladan MB, Grid JF, Genjak IJ: Liposomes of Nifedipine and Nifedipine-cyclodextrin complex: Calorimetrical and plasma stability comparison. Eur J Pharm Sci 1996, 4(3): 359-366.

15. Ramesh KVRNS, Chowdary KPR: Improvement of the Dissolution Rate and Efficiency of Nifedipine by Solid Dispersion in PVP-MCC and HPC-MCC. Ind J Pharm Sci 1994, 56: 5-12.

16. Ouyang D, Nie S, Li W, Guo H, Liu H, Pan W: Design and evaluation of compound Metformin/Glipizide elementary osmotic pump tablets. J Pharm Pharmacol 2005, 57: 817-820. 
17. Haslam JL, Rork GS: Controlled Porosity Osmotic Pump. U.S. Patent 4,880,631, November 141989.

18. Moore JW, Flanner HH: Mathematical comparison of dissolution profiles. Pharm Dev Technol 1996, 20(1): 64-74.

19. Verma RK, Garg S: Development and evaluation of osmotically controlled oral drug delivery system of glipizide. Eur J Pharm Biopharm 2004, 57: 513-525.

20. Schultz P, Kleinebudde CK: A new multiparticulate delayed release system. Part I: dissolution properties and release mechanism. J Control Release 1997, 47(2): 181-189.

21. Costa P, Lobo JMS: Modelling and comparison of dissolution profiles. Eur J Pharm Sci 2001, 13: 123-133.

22. Ritschel WA: Biopharmaceutic and pharmacokinetic aspects in the design of controlled release peroral drug delivery systems. Drug Dev Ind Pharm 1989, 15: 1073-1103.

23. Sood A, Panchagnula R: Design of controlled release delivery systems using a modified pharmacokinetic approach: a case study for drugs having a short elimination half-life and a narrow therapeutic index. Int J Pharm 2003, 261: 27-41.

24. Sheskey P, Pacholke K, Sackett K, Maher L, Polli J: Roll compaction granulation of a controlled release matrix tablet formulation containing HPMC: effect of process scale-up on robustness of tablets, tablet stability, and predicted in vivo performance. Pharm Technol 2000, 24: 30-52.

25. Ritschel WA, Kearns GL: Pharmacokinetic parameters of important drugs. Handbook of Basic Pharmacokinetics. 2 edition. American Pharmaceutical Association. Washington DC; 1999, 479-503.

26. Wieselgren I: Pharmacokinetic and pharmacodynamic evaluation of metoprolol controlled release (CR/ZOK) $50 \mathrm{mg}$ in young subjects. J Clin Pharmacol 1990, 30: 28-35.

27. Zentner GM, Rork GS, Himmelstein KJ: The controlled porosity osmotic pump. J Control Rel 1985, 1(3): 269-282.

28. Appel $L E$, Zentner $G M$ : Use of modified ethyl cellulose lattices for microporous coating of osmotic tablets. Pharm Res 1991, 8(5): 600-604.

29. Rowe RC: Molecular weight dependence of the properties of ethylcellulose and hydroxypropyl methylcellulose films. Int J Pharm 1992, 8: 405-408.

30. Kamba M, Seta Y, Kusai A, Ikeda M, Nishimura K: A unique dosage form to evaluate the mechanical destructive forces in the gastrointestinal tract. Int J Pharm 2000, 208(1): 61-70.

31. Kamba M, Seta Y, Kusai A, Nishimura K: Evaluation of the mechanical destructive force in the stomach of dog. Int J Pharm 2001, 228(2) 209-217.

32. Jensen $J L$, Appel LE, Clair JH, Zentner GM: Variables that affect the mechanism of drug release from osmotic pumps coated with acrylate/ methacrylate copolymer latexes. J Pharm Sci 1995, 84(5): 530-533.

doi:10.1186/1476-511X-10-51

Cite this article as: Kumaravelrajan et al:: Development and evaluation of controlled porosity osmotic pump for Nifedipine and Metoprolol combination. Lipids in Health and Disease 2011 10:51.

\section{Submit your next manuscript to BioMed Central and take full advantage of:}

- Convenient online submission

- Thorough peer review

- No space constraints or color figure charges

- Immediate publication on acceptance

- Inclusion in PubMed, CAS, Scopus and Google Scholar

- Research which is freely available for redistribution

Submit your manuscript at www.biomedcentral.com/submit
Biomed Central 